PAPER • OPEN ACCESS

\title{
Surface chemistry-dependent antiviral activity of silver nanoparticles
}

To cite this article: Terica R Sinclair et al 2021 Nanotechnology 32365101

View the article online for updates and enhancements.

The Electrochemical Society

cal science \& technology 2021 Virtual Education

\section{Intensive Short Courses}

Sun, Oct 10 \& Mon, Oct 11

Providing students and professionals with in-depth education on a wide range of topics

Early registration deadline: Sep 13, 2021 


\title{
Surface chemistry-dependent antiviral activity of silver nanoparticles
}

\author{
Terica R Sinclair ${ }^{1,2}$ (1), Sanne K van den Hengel ${ }^{2,3}$, Brahzil G Raza ${ }^{2}$, \\ Saskia A Rutjes ${ }^{3}$, Ana Maria de Roda Husman ${ }^{3,4}$, \\ Willie J G M Peijnenburg ${ }^{3,5}$, H (Erik) D W Roesink ${ }^{1}$ and Wiebe M de Vos $^{1}$ (1) \\ ${ }^{1}$ Membrane Science \& Technology, MESA + Institute for Nanotechnology, University of Twente, Faculty \\ of Science and Technology, PO Box 217, 7500 AE Enschede, The Netherlands \\ ${ }^{2}$ Wetsus, European Centre of Excellence for Sustainable Water Technology, Oostergoweg 9, 8911 MA \\ Leeuwarden, The Netherlands \\ ${ }^{3}$ National Institute for Public health and the environment (RIVM), A van Leeuwenhoeklaan, 9, 3721 MA \\ Bilthoven, The Netherlands \\ ${ }^{4}$ Institute of Risk Assessment Sciences, IRAS within the faculties of Veterinary Medicine, Medicine and \\ Sciences of Utrecht University, The Netherlands \\ ${ }^{5}$ Institute of Environmental Sciences (CML), Leiden University, PO Box 9518, 2300 RA Leiden, The \\ Netherlands
}

E-mail:w.m.devos@utwente.nl

Received 22 February 2021, revised 15 April 2021

Accepted for publication 20 May 2021

Published 17 June 2021

\section{Abstract}

The toxicity towards viruses of silver nanoparticles (AgNPs) has been reported to be dependent on several factors such as particle concentration, size, and shape. Although these factors may indeed contribute to the toxicity of AgNPs, the results presented in this work demonstrate that surface chemistry and especially surface charge is a crucial factor governing their antiviral activity. Here, this work investigated the influence of capping agents representing various surface charges ranging from negative to positive. These AgNPs were capped with citrate, polyethylene glycol (PEG), polyvinylpyrrolidone (PVP) mercaptoacetic acid (MAA) and (branched polyethyleneimine (BPEI). We show that AgNPs exhibited surface charge-dependent toxicity towards MS2 bacteriophages. Among the capping agents under investigation, BPEI capped AgNPs (Ag/BPEI) exhibited the highest reduction of MS2 resulting in $\geqslant 6 \log _{10}$-units reductions, followed by $4-5 \log _{10}$-units reductions with PVP and PEG capping's and 3-4 $\log _{10}$-units with MAA and citrate cappings. Bare nanoparticles reported a mere $1-2 \log _{10}$-units reduction. Electrostatic interaction between the positively charged BPEI-coating and the negatively charged virus surface played a significant role in bringing the MS2 closer to toxic silver ions $\left(\mathrm{Ag}^{+}\right)$. Further results obtained from TEM showed that $\mathrm{Ag} / \mathrm{BPEI}$ nanoparticles could directly damage the structure of the MS2 bacteriophages. AgNPs and cationic capping agents' observed synergy can lead to much lower and much more efficient dosing of AgNPs for antiviral applications.

Supplementary material for this article is available online

Keywords: silver nanoparticles, antiviral, stabilisation

(Some figures may appear in colour only in the online journal) of the Creative Commons Attribution 4.0 licence. Any further distribution of this work must maintain attribution to the author(s) and the title of the work, journal citation and DOI.

\section{Introduction}

Infectious diseases are responsible for more than $20 \%$ of global mortality, and one of the leading causes of such 
diseases are viruses, accounting for about one-third of these deaths [1]. Unsafe drinking water, inadequate water availability for hygiene, and lack of sanitation access contribute to almost $90 \%$ of deaths from diarrheal diseases [2]. Furthermore, nearly half of all emerging pathogens are viruses [3]. One approach to prevent viral infection is vaccination. However, only a limited amount of vaccines exist.

Moreover, vaccinations against viruses which exists, there is no complete distribution and availability in all parts of the world [4]. An important treatment option is antiviral drugs after infection, but just like vaccines, only a limited amount of approved antivirals are available, and they are virus-specific. Therefore, to prevent emerging infectious diseases including those from viral infections, improved access to safe water, sanitation, and hygiene remains of utmost importance.

Metallic nanoparticles are considered innovative antiviral agents [5] that could be used in conjunction with other disinfection methods. Metallic nanoparticles have been developed because of their unique physical and chemical properties [6]. Silver nanoparticles (AgNPs) are known to be broadspectrum antimicrobial agents and are currently the most widely commercialised nanomaterials [7, 8]. Silver ions have long been known to exert potent antimicrobial activity on many species of bacteria [9-12] and various viruses [5, 13-15]. For these reasons, silver and silver-based compounds have been extensively applied in multiple consumer products, as antimicrobial coatings and surfaces [16-19]. From literature, essential outcomes have typically shown an inverse proportionality between the size of the nanoparticles and their antiviral activity $[13,20,21]$. The smaller the size of the nanoparticle, the greater the antiviral capabilities [5]. Moreover, the higher the nanoparticles' concentration, the more dangerous and undesirable it is for human exposure [5, 22]. Thus, an ideal system employing nanoparticles should have excellent antiviral capabilities at the lowest possible concentration.

However, due to the decrease in size compared to bulk materials, nanoparticles tend to have higher surface energy, leading to instability [23]. Hence nanoparticles often require capping or stabilisation agents to aid their stability and to prevent coagulation. Capping agents work through various mechanisms, commonly categorised in five types: steric stabilisation, electrostatic stabilisation, depletion stabilisation, stabilisation by hydration forces and stabilisation by Van der Waals forces [24]. Multiple mechanisms can occasionally occur with particular capping agents, like branched polyethyleneimine (BPEI). AgNPs are stabilised both electrostatically and sterically due to BPEI's charge and its branched and flexible structure [25].

Besides the stabilisation effect of capping agents, they are beneficial for the controlled synthesis of nanoparticles and achieve specific sizes and monodispersity. Furthermore, capping agents have substantial effects on properties such as size, shape, and solvent interaction [26]. Therefore, the choice of capping agent can be crucial when designing nanoparticles for a particular application. For example, having capping agents on AgNPs surfaces in antimicrobial studies resulted in nanoparticles' enhanced antimicrobial activity [27]. The conventional capping agents used in bottom-up approaches for metallic nanoparticle synthesis ( $\mathrm{Au}, \mathrm{Pt}$, and $\mathrm{Ag}$ ) are polymers and surfactants [28]. Many other stabilisers such as natural polysaccharides, chitosan, alginate, and cellulose and its derivatives can be used to stabilise metallic nanoparticles.

Studies have shown that the antimicrobial activity of AgNPs capped with BPEI had higher activity compared to that of nanoparticles capped with PVP and citrate [29]. The mechanism of silver nanoparticle's toxicity could involve a combination of both physical and chemical interactions. Badawy et al also suggested a direct correlation between the toxicity and the silver nanoparticle's surface charge [25]. The increase in toxicity of the NPs was proportional to the positive increase in the zeta potential. Not only do the stabilisers improve the stability of the AgNPs, but they also influence the antimicrobial activity of the nanoparticle [25, 28, 29].

Given the significant effect of capping agents on the toxicity towards bacteria and the other nanoparticles' properties, it becomes vital to understand the impact of a capping agent on metallic nanoparticles' antiviral activity. Interestingly such nanoparticles could act as broad-spectrum antivirals while still being non-toxic to humans [5, 30].

Enteroviruses can cause a broad-spectrum of diseases in humans, and as such were the main focus of this work. Enteroviruses are single-stranded (ss) RNA viruses with an icosahedrally shaped capsid ranging in size between 20 and $30 \mathrm{~nm}$. Several phages are in the same size range as enteroviruses like $\Phi X 174$ and MS2, which on average are $25 \mathrm{~nm}$. However, because its size and structural properties ss RNA) are similar to those of many human pathogenic enteric viruses and it can be quantified more efficiently and faster, the bacteriophage MS2 has been widely used as an indicator. One bacterial host for MS2 is Escherichia coli (E. coli), and therefore, MS2 is also frequently found in sewage and animal faeces. Like noroviruses, MS2 is adapted to the intestinal tract, and makes it interesting for our experiments, to generally mimic the enteroviruses it represents.

Surrogates are selected based on multiple similarities to the pathogen, such as morphology, genome size and structure, and environmental characteristics. MS2's properties, such as morphology and survival in the environment, have been likened to many enteric viruses. Due to these reasons, MS2 has been used as a surrogate for pathogenic enteroviruses for disinfection testing on surfaces, in water and food; modelling the movement and survival of pathogens in different environments, and transfer properties from surfaces. For this reason, we have also chosen to use MS2 as our surrogate virus in our experiments [31-36].

In this study, we investigate the antiviral activity of AgNPs capped with several capping agents namely, branched polyethyleneimine (Ag/BPEI), mercaptoacetic acid (Ag/ MAA), citrate (Ag/Citrate), polyethylene glycol (Ag/PEG) and polyvinylpyrrolidone (Ag/PVP) against MS2 bacteriophages. While the focus is on the effect as a stabiliser, the additional effects of change in nanoparticle stock concentration, exposure time and NP size on reducing the viral titre of MS2 were also investigated as a comparison. 
<smiles>CCCNCCN(CCN)CCN(CCNCCN)CCN(CCNC)CCN(CCN)CCN</smiles>

Branched Polyethylenimine (BPEI)<smiles>O=C([O-])CC(O)(CC(=O)O)C(=O)[O-]</smiles>

\section{Citrate}<smiles>COCCC(C)O</smiles>

Polyethylene Glycol (PEG)<smiles>O=C(O)CS</smiles>

Mercaptoacetic acid (MAA)<smiles>CCC(N1CCCC1=O)C(C)(C)C</smiles>

Polyvinylpyrrolidone (PVP)

Figure 1. Chemical structures of the capping agents studied.

\section{Experimental section}

\subsection{Materials}

A silver neutraliser solution was prepared based on a technique described by Butka et al [37]. It contained $11.5 \mathrm{~g}$ of $0.93 \mathrm{M}$ sodium thiosulfate and $0.88 \mathrm{M}$ sodium thioglycolate both purchased from Sigma Aldrich, The Netherlands. The stock solution was filtered, sterilised, and stored in an acidwashed, sterile glass bottle. Fresh silver neutraliser was prepared on the day of the experiment.

Five samples of AgNPs with different capping agents (figure 1) were received from Nanocomposix, Prague, Czech Republic. The five samples used for these experiments were $\mathrm{Ag} / \mathrm{BPEI}(\mathrm{Mw}=25 \mathrm{kDa}), \mathrm{Ag} /$ citrate, Ag/PEG, Ag/PVP, and $\mathrm{Ag} / \mathrm{MAA}$. Bare AgNPs were synthesised by reducing silver nitrate $\left(\mathrm{AgNO}_{3}\right)$, by sodium borohydride $\left(\mathrm{NaBH}_{4}\right)$ bought from Sigma Aldrich, The Netherlands. All chemicals purchased were used without any purification. Unless specified, all solutions were prepared in Milli-Q water (Milli-Q, Millipore Billerica, MA with resistivity no less than $18.2 \mathrm{M} \Omega \mathrm{cm}$ at $25{ }^{\circ} \mathrm{C}$ ). It should also be noted that initial experiments were also carried out with pristine linear PEI, but poor solubility under the required experimental conditions led us to discontinue these experiments.

\subsection{MS2 bacteriophage and Salmonella typhimurium (WG49)}

The F-specific bacteriophage MS2 was obtained from GAP Enviro-microbial services Ltd. It was enumerated by the double agar overlay method [38], using as a host strain
Salmonella typhimurium, WG49 (Culture collections of public health England). The stock solution MS2 was $4 \times 1011$ plaque-forming units $(\mathrm{PFU}) / \mathrm{ml}$ and stored at $4{ }^{\circ} \mathrm{C}$. Before each experiment, a fresh MS2 working stock was generated by diluting the stock in 1xPBS (phosphate-buffered saline).

\subsection{Preparation and characterisation of nanoparticles}

2.3.1. Synthesis of bare silver nanoparticles. Bare AgNPs were synthesised by a simple wet chemical reduction of silver nitrate salts using sodium borohydride as a reducing agent using an adopted methodology from Noordeen et al [39]. In short, $30 \mathrm{ml}$ of $0.002 \mathrm{M} \mathrm{NaBH}_{4}$ was added to an Erlenmeyer flask while stirring in an ice bath for $20 \mathrm{~min}$. Two $\mathrm{ml}$ of $0.001 \mathrm{M} \mathrm{AgNO}_{3}$ was added dropwise to the reducing agent. As soon as $\mathrm{AgNO}_{3}$ was added, stirring was stopped, and nanoparticles stored in brown bottles at $2{ }^{\circ} \mathrm{C}-4{ }^{\circ} \mathrm{C}$ ( $\mathrm{pH}$ adjusted to 7.0).

2.3.2. Nanoparticle characterisation. Size and morphology characterisation measurements were carried out using a JEOL JEM 1400 transmission electron microscope (TEM). The TEM samples were prepared by depositing a $100 \mu \mathrm{m}$ drop of nanoparticle suspension received on a standard carbon-coated copper TEM grid and dried at room temperature (R.T. $21{ }^{\circ} \mathrm{C}-23^{\circ} \mathrm{C}$ ) for at least an hour before examination in TEM. The particle size distributions were measured using the Malvern zetasizer NanoZS. All samples were suspended in Milli-Q water to give them appropriate structural and 
thermodynamic wetting properties. The zeta potential measurements were carried out also using Malvern zetasizer NanoZS instrument at $25^{\circ} \mathrm{C}$. In a typical experiment, $60 \mu \mathrm{l}$ of the AgNP suspension was added to $10 \mu \mathrm{l}$ of $1 \mathrm{mM} \mathrm{KCL}$ solution and followed by sonication for $15 \mathrm{~min}$. Samples were not filtered before measurements. Endotoxin testing of the nanoparticles was done by a turbidimetric assay using the pyros kinetix ${ }^{\circledR}$ flex 64 incubating kinetic tube reader, at $37{ }^{\circ} \mathrm{C}$ with a wavelength of $660 \mathrm{~nm}$.

2.3.2.1. TEM for NPs and viruses. Morphology of MS2 bacteriophages was observed by TEM using a staining method. The MS2 bacteriophages were stained with $2 \%$ uranyl acetate for $5 \mathrm{~min}$, then analysed. The same was done to observe damages caused by exposure of the MS2 bacteriophages to the different antiviral AgNPs.

2.3.2.2. ICP-OES. Inductively coupled plasma optical emission spectrometry (ICP-OES Perkin Elmer, USA) was used to quantify the concentration of AgNPs synthesised after being digested with $\mathrm{HNO}_{3}$ and $\mathrm{H}_{2} \mathrm{O}_{2}$ according to US EPA 3050B. Intensity data were recorded using the ICP software and were exported to Excel (Microsoft) for data handling and processing. Instrument calibration was achieved by analysis of a blank and four dissolved Ag solutions ranging from 0 to $15 \mathrm{mg} \mathrm{l}^{-1}$ with data collected.

\subsection{Inactivation experiments of silver nanoparticles}

All glassware was washed with deionised water and sterilised by autoclaving at $121{ }^{\circ} \mathrm{C}$ for $15 \mathrm{~min}$ before use. Inactivation experiments were performed at RT in Pyrex borosilicate glass Petri dishes. MS2 bacteriophages with an initial concentration of $4 \times 10^{9} \mathrm{PFU} \mathrm{ml}^{-1}$ were diluted in Milli-Q water $(\mathrm{pH} 7.0)$ by a 100 -fold dilution of the stock $\left(4 \times 10^{11} \mathrm{PFU} \mathrm{ml}^{-1}\right)$. The experiment was initiated by adding an equal volume $(100 \mu \mathrm{l})$ of a nanoparticle solution to the virus suspension. The suspension was shaken with an orbital shaker at $160 \mathrm{rpm}$ during the entire reaction. Samples of $1 \mathrm{ml}$ were taken at pre-determined time intervals and immediately quenched with their respective neutralising agents. Neutralising agents prevent the continuation of antiviral effects after samples were taken. They also prevent the bacteria used for virus enumeration (host) from being affected by the metallic nanoparticles (data not shown). Samples containing silver were neutralised by adding approximately $20 \mu \mathrm{l}$ or $1 \mathrm{ml}$ of the stock neutraliser solution for $20 \mathrm{mg} \mathrm{l}^{-1}$ or $1 \mathrm{gl}^{-1}$ concentrations of AgNPs, respectively. The amount was pre-determined to be sufficient for neutralising the maximum silver concentration (data not shown). After neutralising, $1 \mathrm{ml}$ of each sample was quantified by plaque assay, and the viral titre determined after incubation overnight $(24 \mathrm{~h})$ at $37^{\circ} \mathrm{C}$. The limit of detection was 30 plaques, and for this only plaque counts between 30 and $300 \mathrm{PFU} \mathrm{ml}{ }^{-1}$ were taken into account for the calculations. The limit of quantification (LoQ) is the lowest concentration of MS2 that can reliably be measured by the plaque assay technique used and was found to be $2 \log _{10}$-units. All experiments were repeated at least three times, and the averages and standard deviations were reported. All glassware used to handle MS2 and metallic nanoparticles were soaked in $10 \% \mathrm{HNO}_{3}$ overnight and rinsed with deionised water to remove adsorbed silver and other contaminants.

\section{Results and discussion}

\subsection{Stability and characterisation of synthesised silver nanoparticles}

Waterborne viruses are of significant concern, especially in resource-limited settings. AgNPs are promising antiviral agents $[14,40]$ that can be used to optimise existing water treatment approaches to prevent the transmission of waterborne diseases. AgNPs were previously shown to inactivate/ inhibit enveloped viruses. In this study, we demonstrate their potential against MS2 bacteriophages, a well-known indicator for enteric, non-enveloped viruses [5, 14, 41]. By manipulating silver-based compounds, and reducing their size, their biological and chemical properties are optimised [21, 42]. The MS2 bacteriophage was studied as it is proposed as a benchmark for the validation of experimental and full-scale studies [43-45]. The bacteriophage has also been proposed as a surrogate for pathogenic enteric viruses [46-48].

The commercial and the self-synthesised AgNP particles were characterised using TEM, UV-vis spectroscopy, and zeta potential measurements. The supplier characterised the commercial AgNPs, and certificates of analyses gave this information. The relevant data were extracted from these certificates and can be found in table S1 (available online at stacks.iop.org/NANO/32/365101/mmedia) (Nanoparticle specification) of the supporting information. For all stabilised nanoparticles, we found that they were indeed highly stable with little, or no agglomeration found upon storing between $2{ }^{\circ} \mathrm{C}$ and $4{ }^{\circ} \mathrm{C}$ in the absence of direct sunlight for periods up to three months. The particles' stability was monitored by tracking the dispersity/aggregation biweekly using DLS and every month using TEM. The data can be found in the supporting information, table S3. The polydispersity of all AgNPs is given by the coefficient of variation, which can also be found in the supporting information, table S1.

Figure 2 shows the spherical morphologies and particle size distribution of the synthesised particles. Table 1 gives an overview of the nanoparticles used in this work; table S2, and figure $\mathrm{S} 1$ in the supporting information details the commercial nanoparticles' characterisation with a higher concentration $\left(1 \mathrm{mg} \mathrm{ml}^{-1}\right)$. TEM images revealed quasi-spherical particles with a narrow size distribution for nanoparticles stabilised with BPEI in figure 2(a) and confirmed by particle size distribution measurements after preparation, 1(d). All capped AgNPs was extremely small, with $d_{50}=10 \pm 2.2 \mathrm{~nm}$ and were found to be virtually free of agglomerates. However, in the absence of capping agent, the synthesised bare nanoparticles agglomerate with a mean size diameter of $d_{50}=200 \pm 8 \mathrm{~nm}$ (figure 2(b)). Next, the concentration of dissolved silver ions $\left(\mathrm{Ag}^{+}\right)$was measured ICP-OES. In figure 1 , we show typical results of the characterisation of 

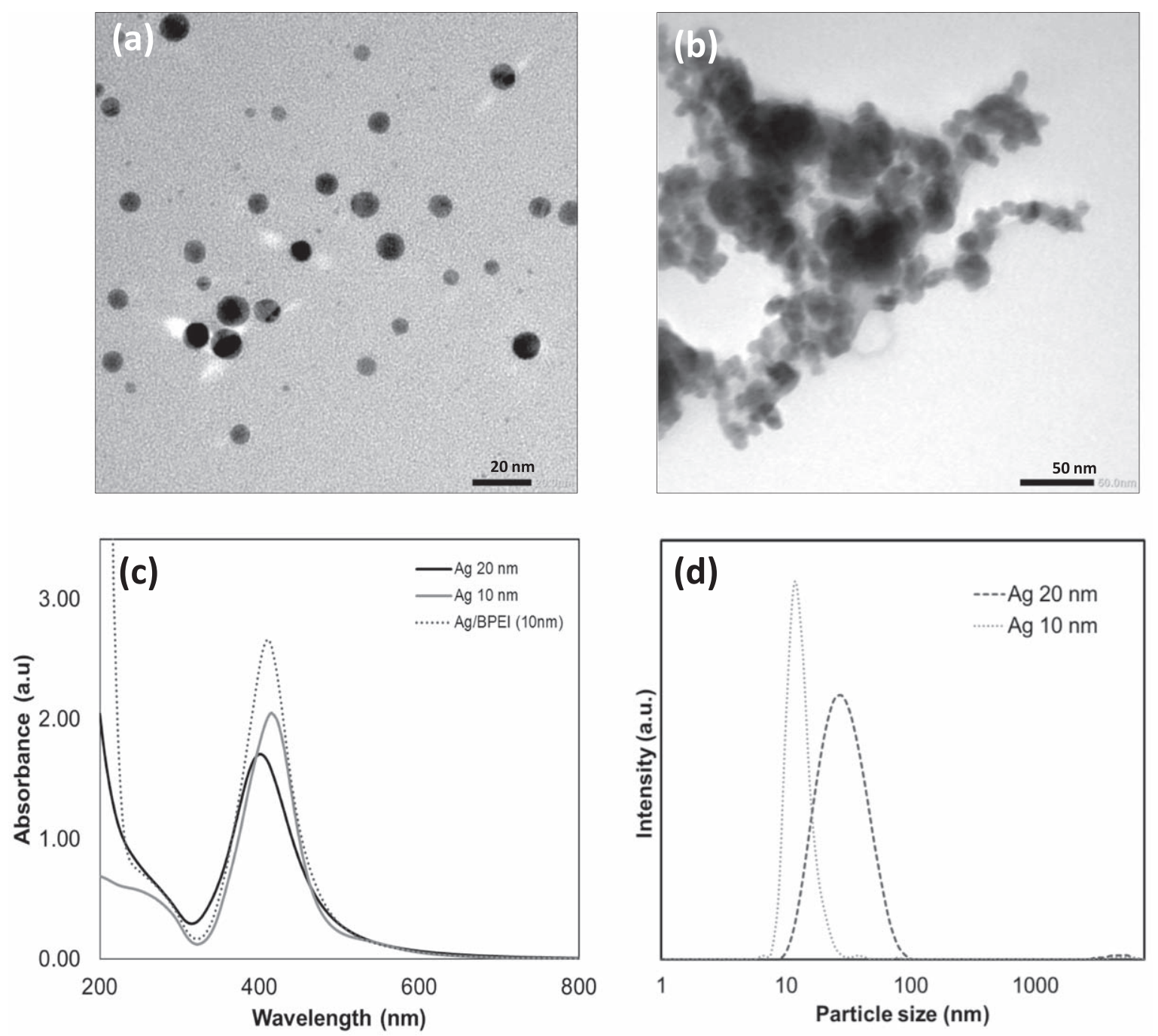

Figure 2. TEM images of (a) BPEI stabilised silver nanoparticle (Ag/BPEI, with scale bar $20 \mathrm{~nm}$ ). (b)Agglomerated bare AgNPs (without capping agent with a scale bar of $50 \mathrm{~nm}$ ), suspended in Milli-Q water. (c) UV-vis spectra of capped and bare nanoparticles and (d) Average $\mathrm{z}$ size of bare nanoparticles in Milli-Q water.

some of the AgNPs used in this investigation. It is also clear from UV-vis spectra that the synthesised nanoparticles exhibited the characteristic surface plasmon resonance (SPR) band, expected for AgNPs. The maximum absorption peaks were between 415 and $420 \mathrm{~nm}$ for silver and shown in figure 2(c). The Mie Theory calculations of the extinction spectra of silver nano-spheres show localised SPR peaks at around $410 \mathrm{~nm}$ [49].

\subsection{Influence of the capping agent on MS2 reduction after short and long exposure times}

Figure 3 shows the viral reduction of MS2 after $30 \mathrm{~min}$ and $24 \mathrm{~h}$ exposure to bare (no capping) or capped (i.e. BPEI, citrate, PEG, MAA, and PVP) AgNPs. Dissolved $\mathrm{AgNO}_{3}$ was used as a positive ion-control $\left(\mathrm{Ag}\right.$-ion $\left.\left(\mathrm{Ag}^{+}\right)\right)$. Here the MS2 stock solution is mixed with demi water, thereby diluting PBS buffer concentration in the sample. This was done as the lower salinities in these samples better represent the conditions found in, for example, surface water. Reduction of MS2 was seen in all Ag-containing samples, after $30 \mathrm{~min}$ exposure as well as for $24 \mathrm{~h}$ exposure. Control assays were also conducted, controls were plated at various times during the experiment (in triplicate). This ensured that the conditions during each experiment's duration did not influence the PFU in stock MS2 solutions. Nor the CFU in stock bacteria Salmonella enterica. The silver neutraliser was also added to selected controls to verify that it did not influence MS2 inactivation, see supporting information, figures S2, and S3. Additional stability tests were also performed for the MS2 in different water types (supporting information figure S4).

The bare AgNPs without stabilisers showed $1 \log 10$-unit reduction after $30 \mathrm{~min}$ and $2 \log _{10}$-units after $24 \mathrm{~h}$. While at short exposure time, the $\mathrm{Ag}^{+}$ions, showed a $3 \log _{10}$-units reduction and a $4 \log _{10}$-units reduction after prolonged exposure. Notably, citrate-stabilised particles are stabilised differently than the other coated AgNPs, as they are bare NPs dispersed in $2 \mathrm{mM}$ sodium citrate which is also stable in 
Table 1. Overview of the properties of the AgNPs stock solutions used in this study.

\begin{tabular}{|c|c|c|c|c|c|c|c|}
\hline Particle surface & Solvent & Diameter (nm) & Molarity $\left(\mathrm{mmol}^{-1}\right)$ & Number conc. $\left(\right.$ particles $\mathrm{ml}^{-1}$ ) & Mass conc. $\left(\mathrm{mg} \mathrm{ml}^{-1}\right)$ & Zeta potential $(\mathrm{mV})$ & $\overline{\left.\text { Dissolved } \mathrm{Ag}^{+} \mathrm{mg} \mathrm{l}^{-1}\right)}$ \\
\hline $\mathrm{Ag} / \mathrm{PVP}$ & Milli-Q water & $9.4 \pm 2.0$ & 0.185 & $3.8 \times 10^{12}$ & 0.02 & -27 & 10 \\
\hline $\mathrm{Ag} / \mathrm{BPEI}$ & Milli-Q water & $9.0 \pm 1.9$ & 0.185 & $5.2 \times 10^{12}$ & 0.02 & +13.8 & 14 \\
\hline $\mathrm{Ag} /$ citrate & Aqueous $2 \mathrm{mM}$ citrate & $9.6 \pm 1.9$ & 0.185 & $3.6 \times 10^{12}$ & 0.02 & -33 & 9.4 \\
\hline $\mathrm{Ag} / \mathrm{PEG}$ & Milli-Q water & $10.2 \pm 2.4$ & 0.185 & $3.3 \times 10^{12}$ & 0.02 & -22.6 & 10 \\
\hline $\mathrm{Ag} / \mathrm{MAA}$ & Milli-Q water & $8.2 \pm 1.9$ & 0.185 & $3.1 \times 10^{12}$ & 0.02 & -34.3 & 9.8 \\
\hline $\mathrm{Ag} /$ bare & Milli-Q water & $\begin{array}{l}10 \pm 1.6 \\
20 \pm 5.1\end{array}$ & 0.185 & $\begin{array}{r}105 \times 10^{12} \\
2.6 \times 10^{11}\end{array}$ & 0.02 & $-35 \pm 2.3$ & 11 \\
\hline
\end{tabular}


(a)
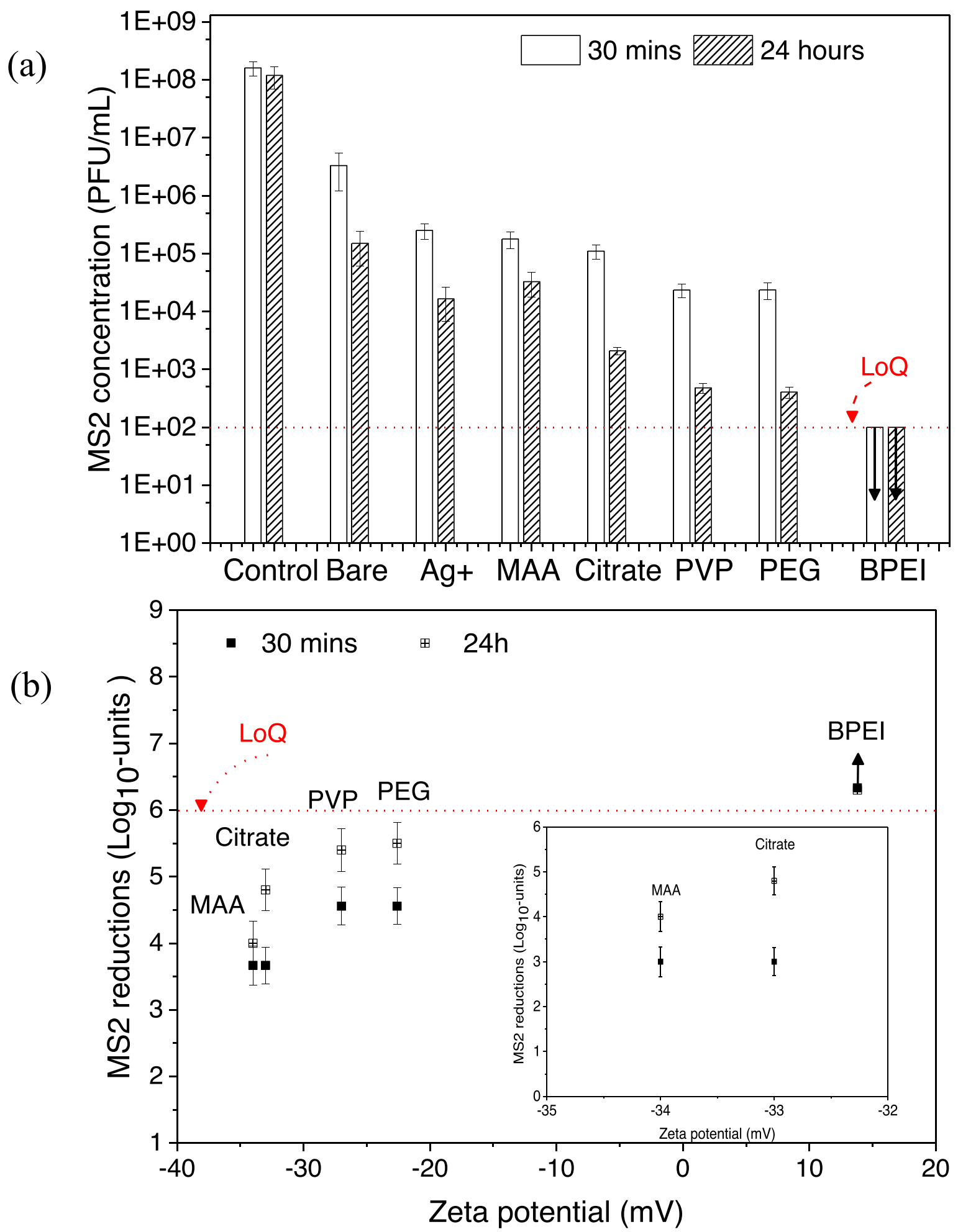

Figure 3. (a) Antiviral activity of $10 \mathrm{~nm}, 0.01 \mathrm{mg} \mathrm{ml}^{-1} \mathrm{AgNPs}$ with different capping agents on MS2 bacteriophages measured as a function of time ( $30 \mathrm{~min}$ and $24 \mathrm{~h}$ ). The reductions were calculated relative to the control samples which were exposed to only Milli-Q water. (b) The $\log 10$-unit reductions as a function of the zeta potential. Each experiment was done in triplicate, and the error bars represent the standard deviations. LoQ denotes the limit of quantification of our method, while arrows indicate that the MS2 concentrations could be lower than the depicted.

water. $\mathrm{Ag} /$ Citrate and $\mathrm{Ag} / \mathrm{MAA} \mathrm{NPs}$ induced a similar reduction ( $3 \log _{10}$-units) of the MS2 concentration as $\mathrm{Ag}^{+}$ after a $30 \mathrm{~min}$ incubation. However, after $24 \mathrm{~h}$, caused a 4 $\log _{10}$-units reduction while citrate induced a higher reduction of $5 \log _{10}$-units. PEG and PVP capped nanoparticles exhibited a $4 \log _{10}$-units reduction over $30 \mathrm{~min}$ which then increased by $1 \log _{10}$-units to give an overall decrease of 5 $\log _{10}$-units after $24 \mathrm{~h}$. 
Moreover, the $\mathrm{Ag} / \mathrm{BPEI}$ resulted in the highest viral titre decrease with no detectable infectious particles found after incubation times. Therefore, exposure of MS2 to Ag/BPEI resulted in at least $\geqslant 6 \log _{10}$-units reductions; however, because of the small volumes used during the exposureexperiment, the LoQ is $2 \log _{10}$-units. For $\mathrm{Ag} / \mathrm{BPEI}$, there were no detectable plaques after incubation and based on the plaque assay's limits of detection and quantification. The reductions could be higher than the $6 \log _{10}$-units recorded. Limitation in quantification is depicted by arrows and indicated on the graphs by a dashed line, meaning that the results could be higher than what is shown in all experiments. These results suggest that the antiviral activity of the different capped AgNP is due to the other capping agents as all nanoparticles had the same concentration of $0.01 \mathrm{mg} \mathrm{ml}^{-1}$, and size $(\sim 10 \mathrm{~nm})$, and zeta potential (except Ag/BPEI NPs). Since Ag/MAA NPs showed the lowest reduction, they were no longer included in the subsequent experiments.

The used capping agents determine, to a large extent the antiviral activity of AgNPs, at least in the range of concentrations and exposure times studied. For bare nanoparticles, the reduced stability led to a meagre reduction (1-2 $\log _{10}$-units). These results confirmed that better dispersion equates to better antiviral activity, which leads to greater reductions. Capping agents for this study were chosen based on their different surface chemistry and charges, with BPEI being positive, PVP- slightly negative, PEG-neutral, and MAA and citrate negative at $\mathrm{pH} 7$. Figure 3, combined with table 1 , could be concluded that the more negative the zeta potential value was, the less toxic the AgNPs are to MS2. The zeta potential of $\mathrm{Ag} / \mathrm{MAA}$ was $-39 \mathrm{mV}$ whereas the zeta potential of $\mathrm{Ag} /$ citrate, $\mathrm{Ag} / \mathrm{PVP}, \mathrm{Ag} / \mathrm{PEG}$ and $\mathrm{Ag} / \mathrm{BPEI}$ were $-33 \mathrm{mV},-27.4 \mathrm{mV},-22.6 \mathrm{mV}$ and $+13.8 \mathrm{mV}$ respectively. The cationic $\mathrm{Ag} / \mathrm{BPEI}$ showed a high reduction of MS2 bacteriophages ( $\geqslant 6 \log _{10}$-units), with the more negative NPs showing lower but significant reductions of 3-5 $\log _{10}$-units over $30 \mathrm{~min}$ and $24 \mathrm{~h}$ ' time periods (figure $3(\mathrm{~b})$ ). Here, at the $\mathrm{pH}$ used, it is important to mention that the virus is negatively charged [50]. From this knowledge, we assume a high degree of repulsion between the negatively charged citrate and MAA AgNPs and MS2 bacteriophages, thus forming an electrostatic barrier that limits the virus-particle interaction, thereby leading to lower toxicity. As the zeta potential gradually becomes less negative, the electrostatic barrier is reduced, which increases the probability of virusparticle interaction with PEG and PVP-coated AgNPs which resulted in higher toxicity leading to $1 \log _{10}$-unit higher reduction. The repulsion then turned into attraction when the bacteriophages were exposed to the positively charged $\mathrm{Ag}$ / BPEI NPs. This change allowed a higher degree of interaction, causing higher toxicity leading to an extreme increase in reduction, above $6 \log _{10}$-units.

From controlled studies, analysing the effects of only the coatings used to stabilise the AgNPs, it was observed that cappings also contribute to the toxicity of the NPs (see supporting information, figure S5). The estimated residual polymers levels or free polymer in the AgNP solution are between 50 and $150 \mu \mathrm{g} \mathrm{ml}^{-1}$ for concentration: $1 \mathrm{mg} \mathrm{ml}^{-1}$ and
$1-3 \mu \mathrm{g} \mathrm{ml}^{-1}$ in concentration: $0.02 \mathrm{mg} \mathrm{ml}^{-1}$, although these numbers may vary depending on the batch. To rule out any effect of residual free capping agents, we tested the viral reductions of just the capping agents, free in solution (see figure S2). These results show convincingly that the polymer needs to be in solutions over $0.03 \mathrm{mg} \mathrm{ml}^{-1}\left(30 \mu \mathrm{g} \mathrm{ml}^{-1}\right)$ far greater than the amount present in the AgNP solutions. As such we rule out any influence of the small amount of free capping agent that might have remained in our AgNP solutions. The reductions were, significantly higher with the addition of the AgNPs in comparison to only the polymer.

Moreover, the results presented in this study suggests that the mechanism of toxicity of AgNPs involves a combination of physical and chemical interactions, where the physical interaction is the limiting factor. $\mathrm{Ag}^{+}$ions interact chemically, and thus a minimal reduction in the MS2 viral titre is seen as compared to AgNPs. As once the electrostatic barrier is passed, the NPs can interact with the virus and cause aggregation and possibly physical damage leading to inactivation.

Furthermore, the significantly higher toxicity exhibited by the Ag/BPEI NPs than the $\mathrm{Ag}^{+}$ions supports the theory of physical interaction being the primary mechanism for AgNPs toxicity compared to only the chemical effects caused by $\mathrm{Ag}^{+}$ alone [51]. It is interesting to observe that most nanoparticles have a better log removal than an equivalent amount of $\mathrm{Ag}^{+}$ ions. This indicates that the slower release of $\mathrm{Ag}^{+}$ions from the AgNPs might, under our conditions, be a more practical approach at virus removal. Moreover, the nanoparticles can have different interactions with the viruses, where contact between particles and viruses could directly damage the virus or virus aggregation.

Additionally, the AgNPs used in this study all had endotoxin levels below 5 E.U. $\mathrm{ml}^{-1}\left(0.05 \mathrm{ng} \mathrm{m}^{-1}\right)$. Furthermore, the levels and exposure should not be harmful to humans, and most tiny mammals [52]. However, precautions to limited leaching or facilitating controlled leaching of the AgNPs over time will be vital in maintaining the drinking water's safety. Most in vitro studies, such as those presented in this work are concentration-dependent, frequently having much higher concentrations than those typically used in invivo experiments. This is demonstrated in figures 4-6 below. The excess amounts of AgNPs are used to maximise their potential as antivirals against waterborne viruses. Therefore, in vitro exposures do not readily replicate the lower concentrations expected in in-vivo exposures. Although there has been significant progress in elucidating the mechanism of AgNPs, the immediate impact or long term effect on human health is still not fully understood. It requires further research $[5,22,53-56]$.

\subsection{Influence of concentration on the antiviral activity}

To analyse the effect of concentration, MS2 reduction after exposure to 0.01 and $0.05 \mathrm{mg} \mathrm{ml}^{-1}$ AgNPs for $30 \mathrm{~min}$ was compared (figure 4).

Principally, for all AgNP samples, except BPEI-coated NPs, a noticeable increase in $\log _{10}$-unit reduction of MS2 was 


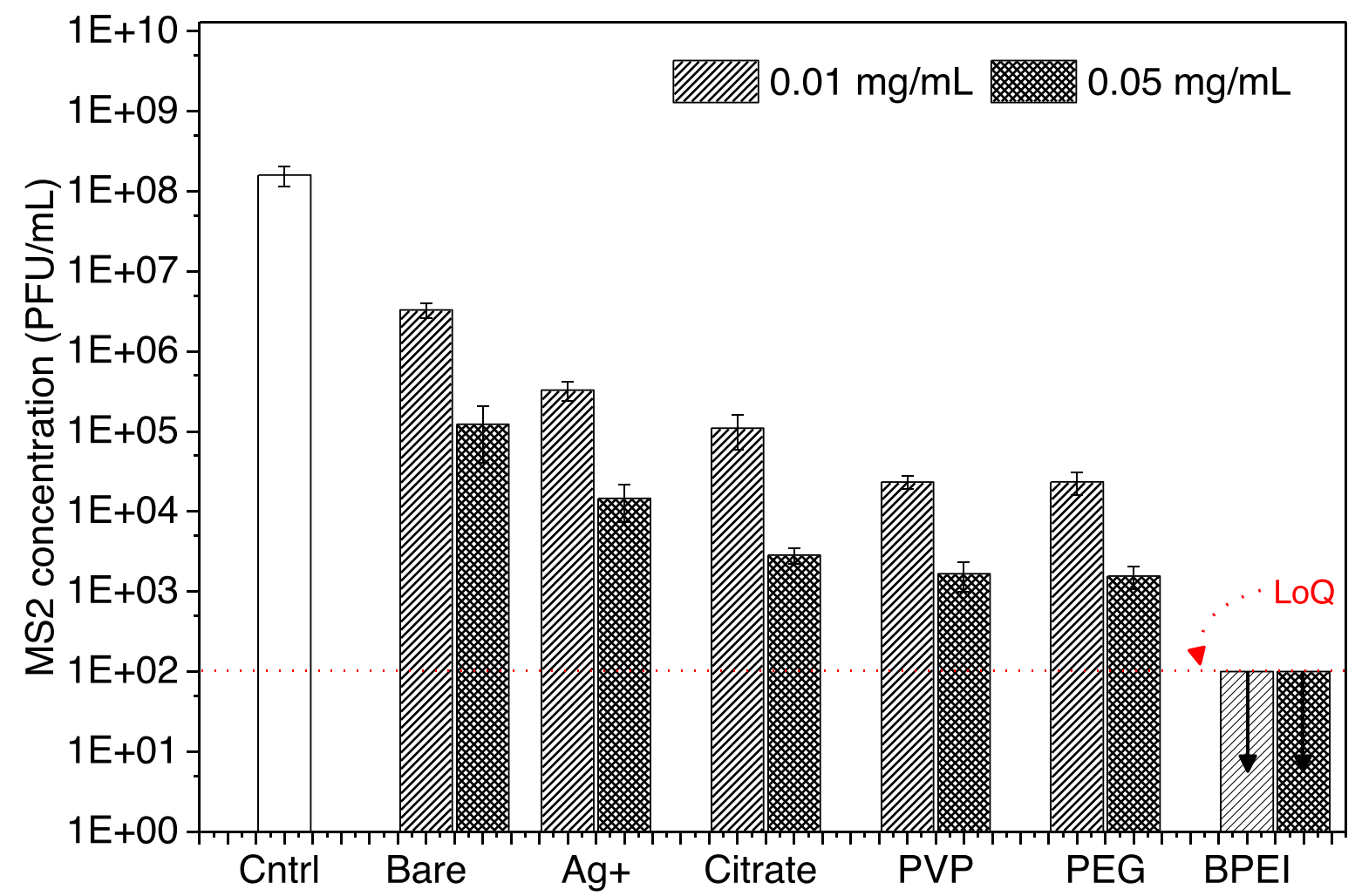

Figure 4. MS2 reduction after exposure to bare AgNPs and AgNPs bearing different capping agents at two exposure concentrations. The AgNPs were exposed for $30 \mathrm{~min}$. The reductions were calculated relative to the control sample, which was exposed to Milli-Q water. Each experiment was done in triplicate, and the error bars represent the standard deviations. LoQ denotes the limit of quantification of our method, while arrows indicate that the MS2 concentrations could be lower than the depicted.

seen when exposed to the highest stock concentration. The increased concentration of $\mathrm{Ag}^{+}$, bare AgNPs, Ag/PVP, and $\mathrm{Ag} / \mathrm{PEG}$ resulted in a $1 \log _{10}$-unit higher reduction. However, $\mathrm{Ag} /$ citrate had a $2 \log _{10}$-units difference in reduction between the high and low concentrations, with 3 and $5 \log _{10}$-units reductions, respectively. In the case of $\mathrm{Ag} / \mathrm{BPEI}$, no infectious particles were detected after exposure at both concentrations, and therefore, the effect of concentration could not be elucidated in this case.

Due to the total inactivation of MS2 after exposure to the used concentrations of $\mathrm{Ag} / \mathrm{BPEI}$ NPs, additional experiments were performed with a dilution range of the Ag/BPEI NPs (figure 4).

In figure 5, it is shown that in case of lower concentration of $\mathrm{Ag} / \mathrm{BPEI}$, there is a decrease in the reduction of the viral titre. However, even at low concentrations of 0.005 and $0.0025 \mathrm{mg} \mathrm{ml}^{-1}$, the nanoparticles could induce significant reductions of 4.8 and $3 \log _{10}$-units, respectively. Additionally, when the concentration was further lowered to $0.001 \mathrm{mg} \mathrm{ml}^{-1}$, the reductions become minimal, at approximately $1 \log _{10}$-unit or less.

With the high log reductions observed for Ag/BPEI, it becomes essential to demonstrate that this stems from a synergy between Ag nanoparticles and their PEI capping, rather than just an effect of the added BPEI. For this, the log reduction of $\mathrm{Ag} / \mathrm{BPEI}$ and free BPEI chains is compared in figure 6 . BPEI in very low concentration $\left(0.003 \mathrm{mg} \mathrm{ml}^{-1}\right)$ did not affect the virus but at higher concentration $\left(3 \mathrm{mg} \mathrm{ml}^{-1}\right)$ achieved reductions of approximately $3 \log _{10}$-units. Moreover, the BPEI and AgNPs combination reached reductions with a minimum of at least $6 \log _{10}$-units reduction depending on the concentration used.

BPEI capped nanoparticles perform much better than uncapped Ag nanoparticles or BPEI polymer chains. The cationic BPEI allows the AgNP to approach or even bind to an anionic virus, enabling direct contact leading to a much more efficient reduction.

A single-step growth curve experiment was performed to provide more information about the phage infection cycle to depict the differences in BPEI treated and untreated samples' growth curves. However, due to the Ag/BPEI nanoparticle's strong inactivating capabilities, no conclusive deductions from this experiment and no relevant findings could be presented in this study.

\subsection{Influence of size on the antiviral activity}

Particle properties that affect toxicity include shape, surface coating, surface charge, and size [16]. Therefore, an additional investigation was carried out to determine the effect of size on the antiviral activity of the AgNPs stabilised with different capping agents (figure 6).

The particle concentration $\left(0.01 \mathrm{mg} \mathrm{ml}^{-1}\right)$ and time ( 30 min) were kept constant, and only the particles' size varied. Limited commercial availability of a wide range, saw 10, 20 and $40 \mathrm{~nm}$ NPs being used in size-dependency 


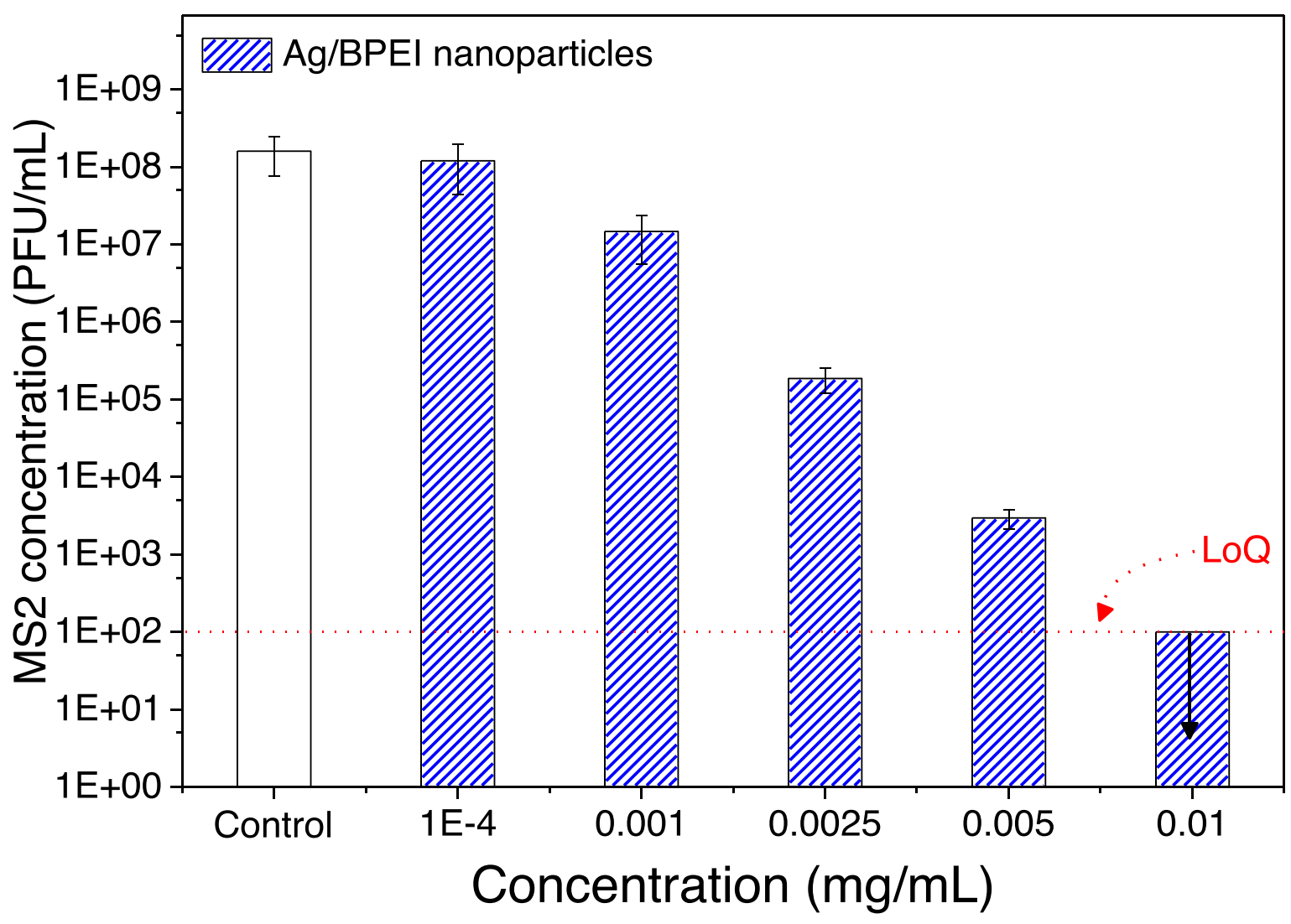

Figure 5. Antiviral activity of Ag/BPEI NPs on MS2 bacteriophages at different concentrations, measured after 30 min. Each experiment was carried out in triplicate, and the error bars represent the standard deviation. LoQ denotes the limit of quantification of our method, while arrows indicate that the MS2 concentrations could be lower than the depicted.

experiment for consistency. Bare AgNPs were synthesised having 10 and $20 \mathrm{~nm}$ diameters. AgNPs with a diameter of $40 \mathrm{~nm}$, was found to be a challenge to reproduce, and as such, there are no results available for this larger size. The bare synthesised AgNPs induced similar reductions as those observed in the time and concentration-dependent experiments. There was a $2 \log 10$-units reduction for the smallest size, which decreased to $1 \log _{10}$-unit reduction for the $20 \mathrm{~nm}$ particles. The control $\mathrm{Ag}^{+}$again induced a $3 \log _{10}$-units reduction, while, $\mathrm{Ag} /$ citrate nanoparticles regardless of size, induced a $3 \log _{10}$-units reduction. Ag/PVP caused a 4 $\log _{10}$-units reduction for 10 and $20 \mathrm{~nm}$ NPs, which later decreased to $3 \log _{10}$-units of reduction for the $40 \mathrm{~nm}$ AgNPs.

Furthermore, $\mathrm{Ag} / \mathrm{PEG}$ had similar behaviour as the citrate with a constant $4 \log _{10}$-units decrease for all sizes. These results suggest that even a slight increase of a few tens of nanometres in particle size can cause a reduction in the antiviral activity of AgNPs and thus, lower reductions of the viral titre, irrespective of the stabilising agent used. Equally, $\mathrm{Ag} / \mathrm{BPEI}$ nanoparticles regardless of concentration, time, and size, induced the highest reduction, with $\geqslant 6 \log _{10}$-unit reductions of the MS2 viral titre.

Mainly, our results in figure 7 show that the smaller $(10 \mathrm{~nm})$ nanoparticles induced or resulted in higher $\log _{10}$-unit reductions when compared to the larger (20 and $40 \mathrm{~nm}$ ) particles. The inverse proportionality of size to toxicity is per the previous studies. These studies demonstrated that AgNPs with sizes ranging from 1 to $10 \mathrm{~nm}$ was shown to interact with viruses such as HIV to inhibit viral attachment to the host cells [13]. Additionally, AgNPs with a diameter around $10 \mathrm{~nm}$ were the most effective at blocking the monkeypox virus-host binding and penetration [20]. Moreover, Chen et al also found these results consistent with the adenovirus type 3 [14].

In contrast to HIV and monkey pox viruses, other studies have also demonstrated significant antiviral activity of silver against feline calicivirus [40], human norovirus-like particles [57], poliovirus [58], and murine norovirus [59]. These viruses are more representative viruses for waterborne pathogens and are also similar in structure (non-enveloped) and size. Using a broader size range could further corroborate the effects of size on the silver nanoparticles' antiviral activity.

Sondi and Salopek-Sondi, as well as Tiwari et al also reported that the concentration of AgNPs determines the extent of their antimicrobial effect along with treatment time $[60,61]$. The results in figures 3 and 4 showed that increasing both time and concentration increased the nanoparticles' antiviral effects towards viruses. It is essential to mention that for $\mathrm{Ag} / \mathrm{BPEI}$, a higher $\mathrm{Ag}^{+}$concentration was found in comparison to the other samples (see table 1), an effect that could contribute to improved viral reductions. Still, as we have seen the viral reduction of only $\mathrm{Ag}^{+}$is substantially smaller than that of $\mathrm{Ag} / \mathrm{BPEI}$, and as such, this effect can be expected to contribute only marginally. Moreover, the 


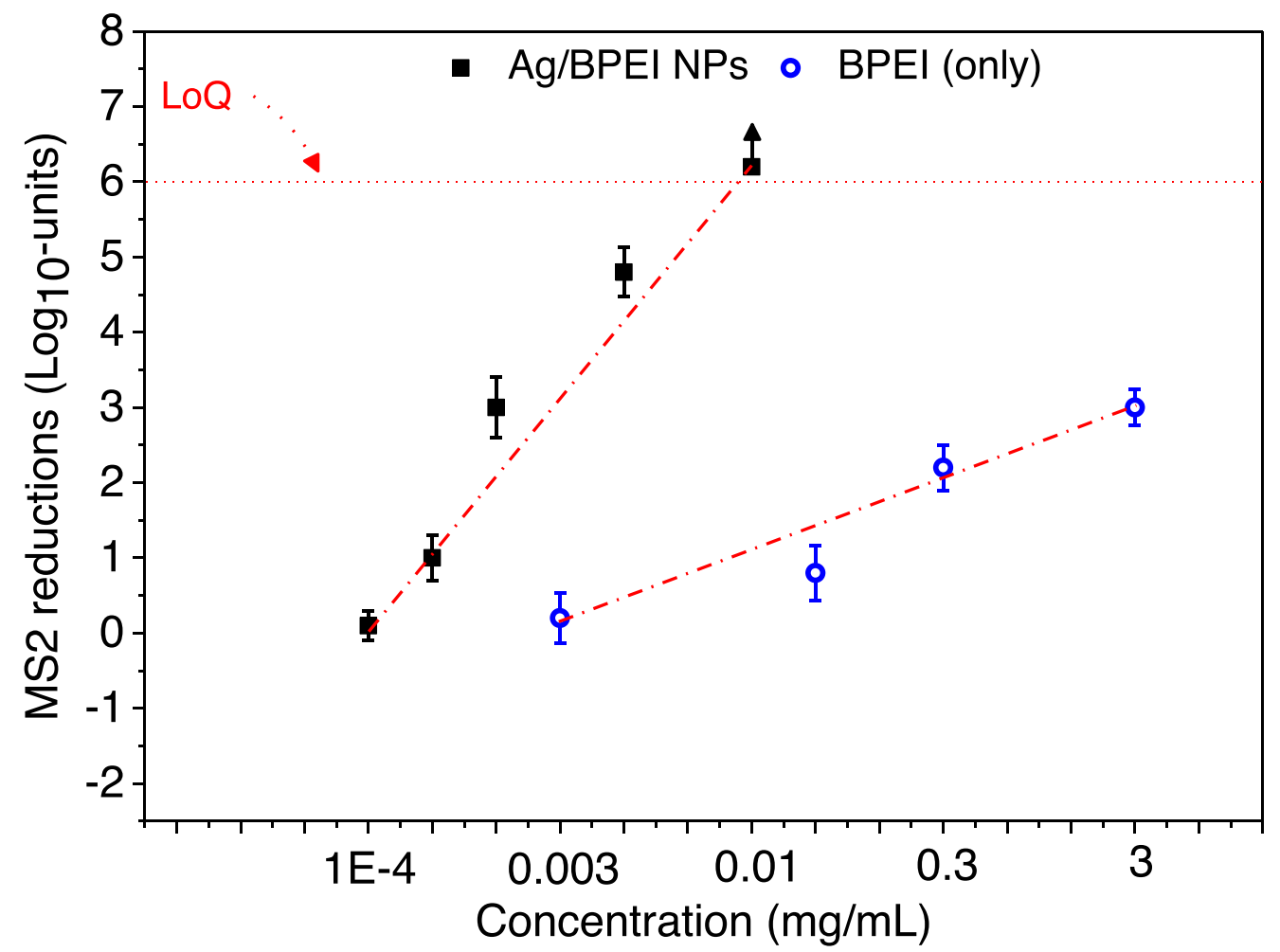

Figure 6. Antiviral activity of bare Ag/BPEI NPs compared to PEI's antiviral activity in solution on MS2 bacteriophages, measured after $30 \mathrm{~min}$. The reductions were calculated relative to the control samples, which were exposed to Milli-Q water. Each experiment was done in triplicate, and the error bars represent the standard deviation. The LoQ indicates the limit of quantification, while the arrow indicates that the reductions could be higher than the depicted.

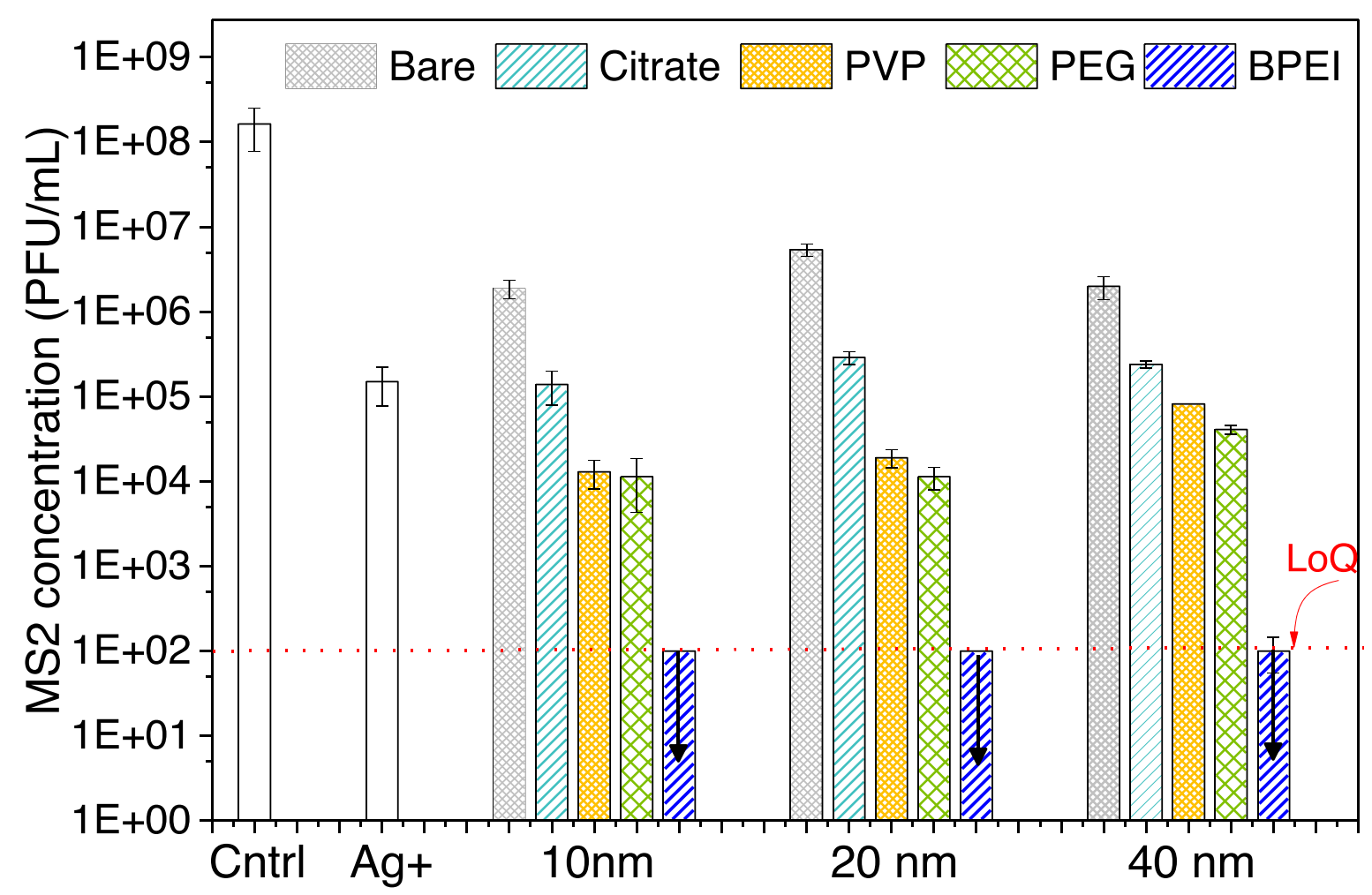

Figure 7. Antiviral activity of AgNPs with different capping agents and size (10, 20, and $40 \mathrm{~nm})$ on MS2 bacteriophages measured after $30 \mathrm{~min}$. The reductions were calculated relative to the control samples which were treated with only Milli-Q water. Each experiment was done in triplicate, and the error bars represent the standard deviations LoQ denotes the limit of quantification of our method. At the same time, arrows indicate that the MS2 concentrations could be lower than the depicted. 

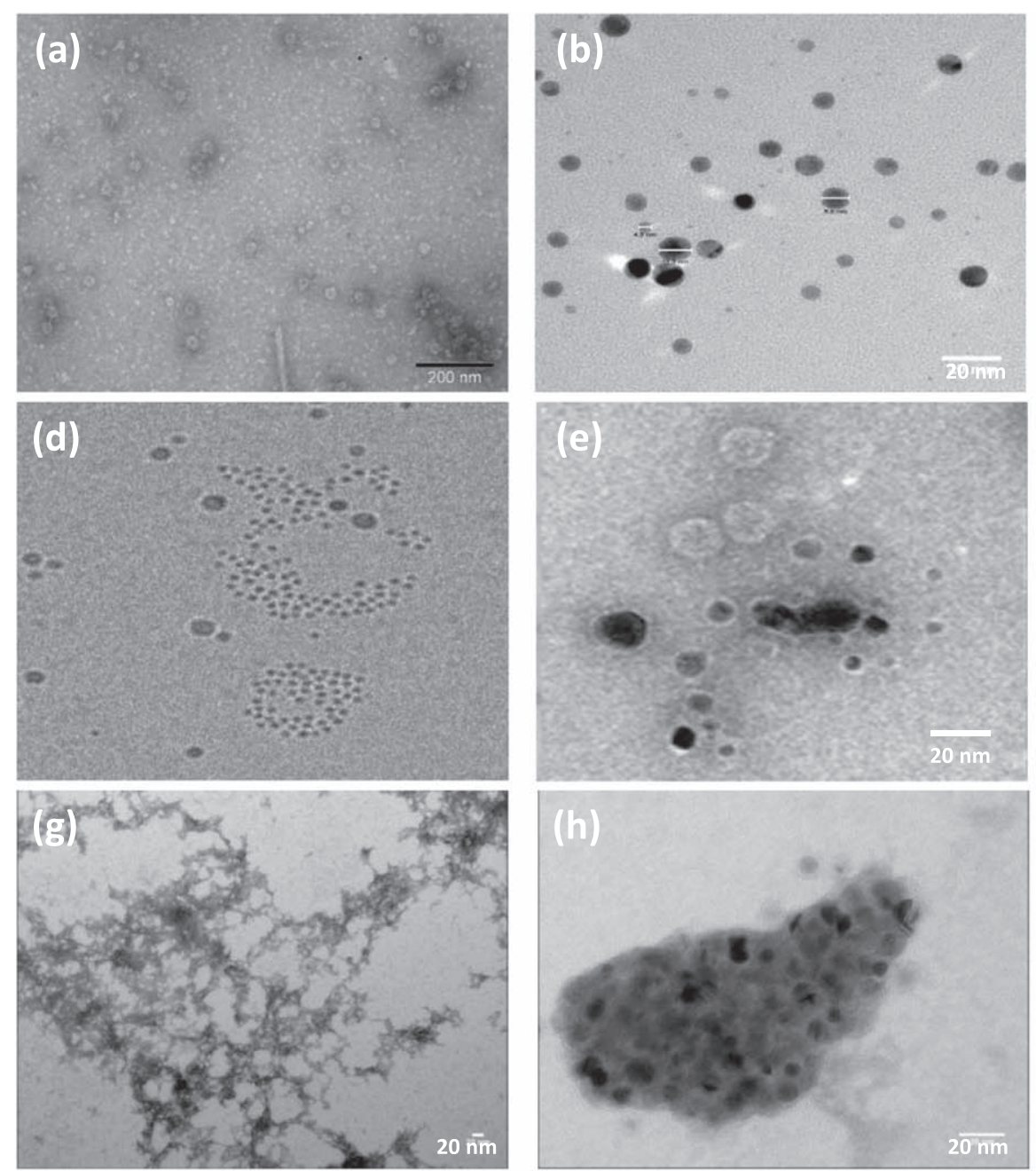
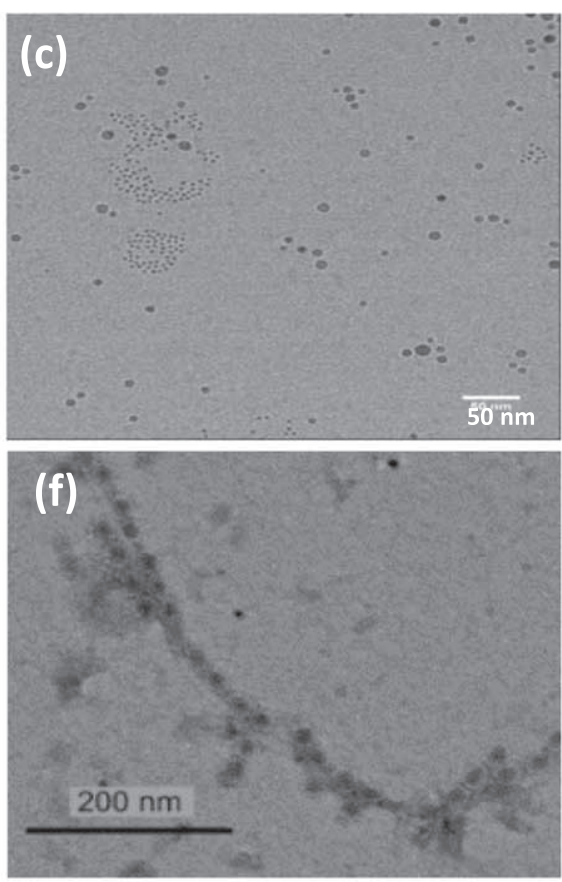

Figure 8. TEM images of the effect of AgNPs on MS2 bacteriophages in different time points. (a) Control sample with MS2 bacteriophages only; (b) BPEI/AgNPs only, (c), and a zoom of (c), image (d) which were previously incubated with $0.01 \mathrm{mg} \mathrm{ml}^{-1}$ of BPEI capped AgNPs after $10 \mathrm{~min}$, while (e)-(g) samples after 30,60 min and $24 \mathrm{~h}$ respectively. While (h) shows a zoom of a section of (g) showing disintegrated bacteriophage particles forming a mass with BPEI/AgNPs is seen compared with the control sample. Samples were stained with $2 \%$ Uranyl acetate for better contrast.

nanoparticle's size, concentration and exposure time significantly affect observed log reductions, with marked changes typically approximately $1 \log _{10}$-unit reduction. However, our results demonstrate for the first time, that not only size, concentration and exposure time [13, 62-64] but also the capping agents used to determine the antiviral effects metallic nanoparticles. Additionally, the impact of capping agent appears to be the dominating effect, with a difference in $\log _{10}$-unit reduction of $>6 \log 10$-units, between bare and $\mathrm{Ag} /$ BPEI (figure 1). For this, we can conclude that capping agents play a crucial role in the production and stabilisation of nanoparticles and the antiviral activity of the nanoparticles.

\subsection{Silver nanoparticle damage of MS2 bacteriophages}

A high reduction of MS2 phages by the BPEI capped AgNPs was observed. For better visualisation and understanding of the mechanism of virus reduction, TEM studies were undertaken.
The MS2 bacteriophage presented an icosahedral shape that was approximately 27-30 nm (figure 8(a)). Figure 8(b) Represents the characterisation of the AgNPs, where the TEM images suggest that the morphology of the AgNPs is spherical and their size distributed in between 10 and $12 \mathrm{~nm}$ range. After incubation with $0.01 \mathrm{mg} \mathrm{ml}^{-1}$ BPEI capped AgNPs for $10 \mathrm{~min}$, the nanoparticles start to form local clusters surrounding the viruses (figures 8 (c) and (d)). As time progresses till 30-60 min, more particles are attracted to the viruses forming larger particle clusters and making difficult it to identify individual virus particles (figures 8(e) and (f)) and progressively increased, thus resembling debris after $24 \mathrm{~h}$ (figure $8(\mathrm{~g})$ ). After $24 \mathrm{~h}$ a zoomed-in section of the clusters in (figure $8(\mathrm{~g})$ ) reveals that the virus is possibly broken and forms large groups with the nanoparticles which can be identified by their crystal lattice (figure $8(\mathrm{~h})$ ). These results suggest that AgNPs exhibit damaging effects on MS2 bacteriophages and that they can induce clustering of viral particles. 
AgNPs play a crucial role in the phage infection of the host bacteria, the mechanism is still not clearly understood, for the AgNP/BPEI the positive charge brought the MS2 and the AgNP close and later attachment which could lead to blocking of the binding sites. The AgNPs often surround the bacteriophage and would most likely attach to the surface of the MS2, not allowing it to infect the bacteria. While on the other hand, the AgNPs also facilitate the infection when it ruptures the bacteria's cell membranes. Thus, we assume an attachment of both MS2 and AgNPs to the surface of the host bacteria. The phages interact differently with the bacteria in the presence of AgNPs.

If the MS2 is inactivated like what we assume is happening in picture $8(\mathrm{e})-(\mathrm{g})$, then the MS2 will be unable to infect the host cell. Verma et al observed what suggested that AgNPs facilitated bacteria cell lysis by the bacteriophages. From their observations, bacteriophages attacked the bacteria, which was clearly shown by the phage head attaching to the bacterial cell, where many phages were seen on the bacterial cell wall's surface. Additionally, it was observed that most often the phages were found to attach with bacterial cell in the proximity of the AgNPs. This work leads the authors to a similar conclusion by the increased bacteriolysis with AgNPs compared with only bacteria and bacteriophage interactions. Verma et al further observed many infection points where they obtained both nanoparticles and bacteriophages [65]. This is normal as bacteria is more susceptible or sensitive to NPs than viruses.

Furthermore, one assumption is that the AgNPs can also facilitate the MS2 infection of the host bacteria, for the virions who are not inactivated or destroyed. AgNPs like many metal oxide nanoparticles change bacterial properties by first attaching to the bacteria's cell wall where it induces some deformity or pitting (see supporting information figure S6) in the bacterial cell structure membrane. The AgNPs damage the cell walls causing increased permeability, leading to accumulation of NPs in the cell membrane and AgNP internalisation. The AgNPs causing the cell membrane to be deformed its properties changed, and there is a reduction in activities, thus facilitating the MS2 to infect the host bacteria. Many factors, such as growth condition, microbial physiological stage, and the ratio of the number of host bacteria to viruses, could affect bacteria and MS2 [65-67].

Moreover, the change in the morphology of the MS2 phages as studied by TEM (figure 8), suggests that the $\mathrm{Ag} /$ BPEI nanoparticles damage the capsid proteins. This damage was confirmed using quantitative polymerase chain reaction (qPCR); details are given in the supporting information (figure S7). The capsid's damage causes a disruption or hindrance of the initial phase of the viral replication cycle and all subsequent events.

Furthermore, the addition of $\mathrm{Ag} / \mathrm{BPEI}$ leads to aggregation of the virus particles [68], another mechanism that might lead to the observed very high $\log _{10}$-unit reductions of MS2 phages activity. This idea is supported by the findings of the plaque assay of the $\mathrm{Ag} / \mathrm{BPEI} \mathrm{NPs}$, as the number of infectious particles after treatment was below the detection limit of the method.
Sondi and Salopek-Sondi et al also stated that AgNPs also possess other intervention characteristics on a virus' life cycle, other than attachment and entry [60]. Previous findings reported that $\mathrm{Ag}^{+}$could affect the genomic material (RNA or DNA) and therefore, the virus' replication ability $[9,35$, 69-71]. AgNPs have also been proven to interact with the genome of the hepatitis B virus [72], adenovirus [14] and HIV [73]. Therefore, based on this, it is reasonable to state that AgNPs could not only directly bind to the capsid proteins of the MS2 bacteriophages but could have also interacted with its genetic material in this case, it is RNA. However, more studies, such as quantitative real-time polymerase chain reaction (qRT-PCR) are needed to confirm this. Also, AgNPs have higher affinity to interact with phosphorus and sulphurcontaining compounds which could cause the nanoparticles to adsorb to the host cells during the plaque assay [13]. This adsorption of the nanoparticle could induce conformational changes of the receptor on the host cell, which would then inhibit the infection of the MS2. Viruses, however, are complex and highly diverse molecules with unique properties like varying capsid chemistries. Thus, their inactivation and infection during experiments are not only affected by the $\mathrm{AgNPs}$ and their chemistries. They are affected by the surface chemistry of the bacteriophage and outlined by Gilcrease et al [74]. This phenomenon is yet another unexplored area of phage and nanoparticle interaction that will require further investigations.

Additionally, cationic polymers interact with RNA electrostatically due to the presence of phosphate in the backbone [75], demonstrating a possible reason for the superior behaviour of the $\mathrm{Ag} / \mathrm{BPEI}$ NPs. Furthermore, the antiviral mechanism of cationic polymers such as BPEI though not fully understood can also offer more insight for the results observed. The structure and size of the BPEI could also modulate its cytotoxicity, as it can potentially cause an increasing burden of reactive oxygen species. Moreover, the effects of BPEI could be attributed to its branching structure and not merely by the presence of low molecular weight amines and other possible impurities and contaminants (if present) [76].

Furthermore, both the size and structure of BPEI could cause the virus's destabilisation by possibly perturbing its intracellular redox homoeostasis. This alarm could also result in a shift in the homoeostasis's balance toward increased oxidative stress [77]. Therefore, oxidative stress could induce cytotoxic responses, which lead to the potential inactivation of the virus.

RNA phages like MS2 are generally unable to cause lysis of their bacterial hosts in this case salmonella when the bacteria is approaching the stationary phase [78]. The mechanisms of cell lysis which leads to inactivation caused by RNA phages like MS2 infections are still not completely understood. Researchers have generally agreed that MS2 causes cell lysis by destroying or disintegrating the structure of the cell membrane of their bacterial host and interacting with the external membrane systems. These interactions then lead to the release of endogenous peptidoglycan (Murein) hydrolases of the host cell $[79,80]$. Based on this, it appears 
that AgNPs are facilitating the host's cell disintegration, followed by the phage infection that results into the increased bacteriolysis. MS2 bacteriophages used low molecular weight hydrophobic proteins; these proteins are sufficient to trigger the host bacteria's lysis. The introduction of nanoparticles increases the complexity of the interactions between bacteriophage and bacteria. These interactions are multifaceted and highly complex. From our experiments, the following findings should be noted:

i. MS2 infection of their bacterial host is different in the presence of AgNPS leading to cell lysis and is possibly designated by the infection point.

ii. AgNPs plays a vital role in phage infection to the host; however, we still need to know more about the mechanism.

iii. The mechanism of AgNP's toxicity involves a combination of physical and chemical interactions.

\section{Conclusions}

The efficiencies of six AgNPs with five different capping agents (Bare, BPEI, PVP, PEG, MAA and citrate) for AgNPs were compared for their antiviral effects on MS2 bacteriophages. Poorly dispersed bare AgNPs provided only relatively low reductions of just $1-2 \log _{10}$-units which increased to 3-4 $\log _{10}$-unit reduction for the better stabilised but strongly negative $\mathrm{Ag} / \mathrm{MAA}$ and $\mathrm{Ag} /$ citrate. For the weakly negative Ag/PVP and Ag/PEG nanoparticles, a 4-5 $\log _{10}$-unit reduction was found. While the $10 \mathrm{~nm}$, cationically stabilised Ag/BPEI with a concentration of $0.02 \mathrm{mg} \mathrm{ml}^{-1}$ induced the highest antiviral activity of at least $\geqslant 6 \log _{10}$-units reduction within $30 \mathrm{~min}$. The surface chemistry plays a significant role; the most negative NPs repel the negative viruses avoiding contact, while for less negative NP's this effect disappears. For the positive $\mathrm{Ag} / \mathrm{BPEI}$, there is an apparent synergetic effect between the polymer and particle. The cationic polymer binding to the negatively charged virus to bring the AgNPs in direct contact with the virus. These encouraging results provide a basis for further research on stabilised metallic silver nanoparticles at low concentrations for potential antiviral applications designated for combating waterborne diseases in a short time.

\section{Acknowledgments}

This work was performed in the TTIW-cooperation framework of Wetsus, European Centre of Excellence for Sustainable Water Technology (www.wetsus.nl). Wetsus is funded by the Dutch Ministry of Economic Affairs, the European Union Regional Development Fund, the Province of Fryslân, and the City of Leeuwarden and the Northern Netherlands provinces. We thank the participants of the research theme 'Virus Control' for their financial support and helpful discussions. We would also like to thank Professor Aldrik Velders, Jan Bart and Anton Bunschoten of the
Department of Agro-technology and Food science, subdivision BioNanotechnology at the University of Wageningen for their assistance with transmission electron microscopy.

\section{Data availability statement}

All data that support the findings of this study are included within the article (and any supplementary files).

\section{Author contributions}

The manuscript was written through the contributions of all authors. All authors have approved the final version of the manuscript. Terica R Sinclair, Sanne K van den Hengel conceived and designed inactivation experiments; Terica $\mathrm{R}$ Sinclair and Brahzil G Raza performed the experiments; Terica R Sinclair, Sanne K van den Hengel, Saskia A Rutjes and Ana Maria de Roda Husman analysed virology data, Terica R Sinclair and W de Vos analysed characterisation data; Terica R Sinclair wrote the paper, and all authors reviewed the article.

\section{ORCID iDs}

Terica R Sinclair (ib https://orcid.org/0000-0002-2874-1375 Wiebe M de Vos (iD https://orcid.org/0000-0002-0133-1931

\section{References}

[1] Lozano R et al 2012 Global and regional mortality from 235 causes of death for 20 age groups in 1990 and 2010: a systematic analysis for the Global Burden of Disease Study 2010 Lancet 380 2095-128

[2] Bos R, Gore F and Bartram J 2008 Safer water, better health: costs, benefits and sustainability of interventions to protect and promote health World Heal. Organ. 160

[3] Taylor L H, Latham S M and Woolhouse M E 2001 Risk factors for human disease emergence. Phil. Trans. R. Soc. B 356 983-9

[4] Plotkin S A 2005 Vaccines: past, present and future Nat. Med. $11 \mathrm{~S} 5$

[5] Galdiero S, Falanga A, Vitiello M, Cantisani M, Marra V and Galdiero M 2011 Silver nanoparticles as potential antiviral agents Molecules 16 8894-918

[6] Cole M T, Mann M, Teo K B K and Milne W I 2015 Emerging Nanotechnologies for Manufacturing (Oxford: William Andrew Publishing)

[7] Project on Emerging Nanotechnologies 2013 Consumer Products Inventory http://nanotechproject.org/cpi

[8] Vance M E, Kuiken T, Vejerano E P, McGinnis S P, Hochella M F and Hull D R 2015 Nanotechnology in the real world: redeveloping the nanomaterial consumer products inventory Beil. J. Nanotechnol. 6 1769-80

[9] Feng Q L, Wu J, Chen G Q, Cui F Z, Kim T N and Kim J O 2000 A mechanistic study of the antibacterial effect of silver ions on Escherichia coli and Staphylococcus aureus J. Biomed. Mater. Res. 52 662-8 
[10] Kim J Y, Lee C, Cho M and Yoon J 2008 Enhanced inactivation of $E$. coli and MS-2 phage by silver ions combined with UV-A and visible light irradiation Water Res. 42 356-62

[11] Ruparelia J P, Chatterjee A K, Duttagupta S P and Mukherji S 2008 Strain specificity in antimicrobial activity of silver and copper nanoparticles Acta Biomater. 4 707-16

[12] Lee H J et al 2011 Antimicrobial polyethyleneimine-silver nanoparticles in a stable colloidal dispersion Colloids Surf. B 88 505-11

[13] Elechiguerra J L et al 2005 Interaction of silver nanoparticles with HIV-1 J. Nanobiotechnol. 36

[14] Chen N, Zheng Y, Yin J, Li X and Zheng C 2013 Inhibitory effects of silver nanoparticles against adenovirus type 3 in vitro J. Virol. Methods 193 470-7

[15] Yahya M T, Straub T M and Gerba C P 1992 Inactivation of coliphage MS-2 and poliovirus by copper, silver, and chlorine Can. J. Microbiol. 38 430-5

[16] Xiu Z, Zhang Q, Puppala H L, Colvin V L and Alvarez P J J 2012 Negligible particle-specific antibacterial activity of silver nanoparticles Nano Lett. 12 4271-5

[17] Secinti K D, Özalp H, Attar A and Sargon M F 2011 Nanoparticle silver ion coatings inhibit biofilm formation on titanium implants J. Clin. Neurosci. 18 391-5

[18] Förch R, Duque L and Lotz A 2014 Antimicrobial bioactive polymer coatings Comprehensive Materials Processing vol 4 (Amsterdam: Elsevier) pp 449-61

[19] Tiller J 2006 Silver-based antimicrobial coatings Polym. Drug Deliv. II 924 (Washington: American Chemical Society) pp 215-31

[20] Rogers J V, Parkinson C V, Choi Y W, Speshock J L and Hussain S M 2008 A preliminary assessment of silver nanoparticle inhibition of monkeypox virus plaque formation Nanoscale Res. Lett. 3 129-33

[21] Shahverdi A R, Fakhimi A, Shahverdi H R and Minaian S 2007 Synthesis and effect of silver nanoparticles on the antibacterial activity of different antibiotics against Staphylococcus aureus and Escherichia coli Nanomed. Nanotechnol. Biol. Med. 3 168-71

[22] Chen X and Schluesener H J 2008 Nanosilver: a nanoproduct in medical application Toxicol. Lett. 176 1-12

[23] Plieth W J 1982 Electrochemical properties of small metal clusters J. Phys. Chem. 86 3166-70

[24] Do Kim K, Han D N and Kim H T 2004 Optimization of experimental conditions based on the Taguchi robust design for the formation of nano-sized silver particles by chemical reduction method Chem. Eng. J. 104 55-61

[25] El Badawy A M, Scheckel K G, Suidan M and Tolaymat T 2012 The impact of stabilization mechanism on the aggregation kinetics of silver nanoparticles Sci. Total Environ. 429 325-31

[26] Raveendran P, Fu J and Wallen S L 2003 Completely 'green' synthesis and stabilization of metal nanoparticles $J$. Am. Chem. Soc. 125 13940-1

[27] Van Phu D et al 2014 Study on antibacterial activity of silver nanoparticles synthesized by gamma irradiation method using different stabilizers Nanoscale Res. Lett. 9162

[28] Kvítek L et al 2008 Effect of surfactants and polymers on stability and antibacterial activity of silver nanoparticles (NPs) J. Phys. Chem. C 112 5825-34

[29] El Badawy A M, Silva R G, Morris B, Scheckel K G, Suidan M T and Tolaymat T M 2011 Surface chargedependent toxicity of silver nanoparticles Environ. Sci. Technol. 45 283-7

[30] Salleh A et al 2020 The potential of silver nanoparticles for antiviral and antibacterial applications: a mechanism of action Nanomaterials 101566
[31] McMinn B R, Ashbolt N J and Korajkic A 2017

Bacteriophages as indicators of faecal pollution and enteric virus removal Lett. Appl. Microbiol. 65 11-26

[32] Kim D K, Kim S J and Kang D H 2017 Inactivation modeling of human enteric virus surrogates, MS2, Q $\beta$, and $\Phi X 174$, in water using UVC-LEDs, a novel disinfecting system Food Res. Int. 91 115-23

[33] Hu J Y et al 2003 Removal of MS2 bacteriophage using membrane technologies In Water Science and Technology 47 163-8

[34] Jacangelo J G, Trussell R R and Watson M 1997 Role of membrane technology in drinking water treatment in the United States Desalination 113 119-27

[35] You J, Zhang Y and Hu Z 2011 Bacteria and bacteriophage inactivation by silver and zinc oxide nanoparticles Colloids Surf. B 85 161-7

[36] Otaki M, Yano K and Ohgaki S 1998 Virus removal in a membrane separation process Water Science and Technology 37 107-16

[37] Butkus M A, Labare M P, Starke J A, Moon K and Talbot M 2004 Use of aqueous silver to enhance inactivation of coliphage MS-2 by UV disinfection Appl. Environ. Microbiol. 70 2848-53

[38] Adams M 1959 Bacteriophages Bacteriophages (New York: Interscience Publishers) p 620 http://cabdirect.org/ abstracts / 19602204111.html

[39] Noordeen S, Karthikeyan K and Parveen M A N 2013 Synthesis of silver nanoparticles by using sodium borohydride as a reducing agent Int. J. Eng. Res. Technol. 2 388-97

[40] Bekele A Z, Gokulan K, Williams K M and Khare S 2016 Dose and size-dependent antiviral effects of silver nanoparticles on feline calicivirus, a human norovirus surrogate Foodborne Pathog. Dis. 13 239-44

[41] Rai M, Yadav A and Gade A 2009 Silver nanoparticles as a new generation of antimicrobials Biotechnol. Adv. 27 76-83

[42] Morones J R et al 2005 The bactericidal effect of silver nanoparticles Nanotechnology 16 2346-53

[43] Bae J and Schwab K J 2008 Evaluation of murine norovirus, feline calicivirus, poliovirus, and MS2 as surrogates for human norovirus in a model of viral persistence in surface water and groundwater Appl. Environ. Microbiol. 74 477-84

[44] Grabow W O K 2001 Bacteriophages: update on application as models for viruses in water Water SA 27 251-68

[45] Hirneisen K A, Black E P, Cascarino J L, Fino V R, Hoover D G and Kniel K E 2010 Viral inactivation in foods: a review of traditional and novel food-processing technologies Comprehensive Rev. Food Sci. Food Saf. 9 3-20

[46] Thurston-Enriquez J A, Haas C N, Jacangelo J, Riley K and Gerba C P 2003 Inactivation of feline calicivirus and adenovirus type 40 by UV radiation Appl. Environ. Microbiol. $69577-82$

[47] Turgeon N, Toulouse M J, Martel B, Moineau S and Duchaine C 2014 Comparison of five bacteriophages as models for viral aerosol studies Appl. Environ. Microbiol. 80 4242-50

[48] Dawson D J, Paish A, Staffell L M, Seymour I J and Appleton H 2005 Survival of viruses on fresh produce, using MS2 as a surrogate for norovirus J. Appl. Microbiol. 98 203-9

[49] Zhao J et al 2005 Alkanethiol mediated release of surface bound nanoparticles fabricated by nanosphere lithography MRS Proc. 9001308

[50] Langlet J, Gaboriaud F and Gantzer C 2007 Effects of pH on plaque forming unit counts and aggregation of MS2 bacteriophage J. Appl. Microbiol. 103 1632-8 
[51] Wood C M, Playle R C and Hogstrand C 1999 Physiology and modeling of mechanisms of silver uptake and toxicity in fish Environ. Toxicol. Chem. 18 71-83

[52] Catherine P, McIntyre A and Reinin G 2009 Reduction in endotoxin levels after performing the prepare for aseptic sort procedure on the BD FACSAria II flow cytometer $B D$ Biosci. Appl. Note

[53] Kim Y S et al 2008 Twenty-eight-day oral toxicity, genotoxicity, and gender-related tissue distribution of silver nanoparticles in Sprague-Dawley rats Inhal. Toxicol. 20 575-83

[54] Panyala N R, Peña-Méndez E M and Havel J 2012 Silver or silver nanoparticles: a hazardous threat to the environment and human health? J. Appl. Biomed. 6 117-29

[55] Schrand A M, Rahman M F, Hussain S M, Schlager J J, Smith D A and Syed A F 2010 Metal-based nanoparticles and their toxicity assessment Wiley Interdiscip. Rev. Nanomed. Nanobiotechnol. 2 544-68

[56] Marambio-Jones C and Hoek E M V 2010 A review of the antibacterial effects of silver nanomaterials and potential implications for human health and the environment J. Nanopart. Res. 12 1531-51

[57] Broglie J J et al 2015 Antiviral activity of gold/copper sulfide core/shell nanoparticles against human norovirus virus-like particles PLoS One $\mathbf{1 0} \mathrm{e} 0141050$

[58] Huy T Q et al 2017 Cytotoxicity and antiviral activity of electrochemical—synthesized silver nanoparticles against poliovirus J. Virol. Methods 241 52-7

[59] De Gusseme B et al 2010 Biogenic silver for disinfection of water contaminated with viruses Appl. Environ. Microbiol. 76 1082-7

[60] Sondi I and Salopek-Sondi B 2004 Silver nanoparticles as antimicrobial agent: a case study on E. coli as a model for Gram-negative bacteria J. Colloid Interface Sci. 275 177-82

[61] Tiwari D K, Behari J and Sen P 2008 Time and dose-dependent antimicrobial potential of Ag nanoparticles synthesized by top-down approach Curr. Sci. 95 647-55

[62] Sotiriou G A and Pratsinis S E 2010 Antibacterial activity of nanosilver ions and particles Environ. Sci. Technol. 44 5649-54

[63] Panacek A et al 2006 Silver colloid nanoparticles: synthesis, characterization, and their antibacterial activity $J$. Phys. Chem. B 110 16248-53

[64] Carlson C et al 2008 Unique cellular interaction of silver nanoparticles: size-dependent generation of reactive oxygen species J. Phys. Chem. B 112 13608-19

[65] Verma K A et al 2019 Advances in nanomedicine and highly sensitive bacteriophage-silver nanoparticle consortium for enhanced Adv. Nanomed.Nanotechnol. Res 1 28-35
[66] Nair S et al 2009 Role of size scale of $\mathrm{ZnO}$ nanoparticles and microparticles on toxicity toward bacteria and osteoblast cancer cells Journal of Materials Science: Materials in Medicine 20235

[67] Lok C N et al 2007 Silver nanoparticles: partial oxidation and antibacterial activities J. Biol. Inorg. Chem. 12 527-34

[68] Gerba C P and Betancourt W Q 2017 Viral aggregation: impact on virus behavior in the environment Environ. Sci. Technol. 51 7318-25

[69] Yamanaka M, Hara K and Kudo J 2005 Bactericidal actions of a silver ion solution on Escherichia coli, studied by energyfiltering transmission electron microscopy and proteomic analysis Appl. Environ. Microbiol. 71 7589-93

[70] Jung W K, Koo H C, Kim K W, Shin S, Kim S H and Park Y H 2008 Antibacterial activity and mechanism of action of the silver ion in Staphylococcus aureus and Escherichia coli Appl. Environ. Microbiol. 74 2171-8

[71] Durán N, Durán M, de Jesus M B, Seabra A B, Fávaro W J and Nakazato G 2016 Silver nanoparticles: a new view on mechanistic aspects on antimicrobial activity Nanomed. Nanotechnol. Biol. Med. 12 789-99

[72] Lu L et al 2008 Silver nanoparticles inhibit hepatitis B virus replication Antivir. Ther. 13 253-62

[73] Lara H H, Ayala-Nuñez N V, Ixtepan-Turrent L and Rodriguez-Padilla C 2010 Mode of antiviral action of silver nanoparticles against HIV-1 J. Nanobiotechnol. 81

[74] Gilcrease E, Williams R and Goel R 2020 Evaluating the effect of silver nanoparticles on bacteriophage lytic infection cycle-a mechanistic understanding Water Res. 181115900

[75] Bloomfield V A 1996 DNA condensation Curr. Opin. Struct. Biol. 6 334-41

[76] Tang M X and Szoka F C 1997 The influence of polymer structure on the interactions of cationic polymers with DNA and morphology of the resulting complexes Gene Ther. 4 823-32

[77] Hall A et al 2015 Polyethylenimine architecture-dependent metabolic imprints and perturbation of cellular redox homeostasis Biochim. Biophys. Acta-Bioenerg. 1847 328-42

[78] Haywood A M 1974 Lysis of RNA phage infected cells depends upon culture conditions J. Gen. Virol. 22

[79] Holtje J V, Fiedler W, Rotering H, Walderich B and Van Duin J 1988 Lysis induction of Escherichia coli by the cloned lysis protein of the phage MS2 depends on the presence of osmoregulatory membrane-derived oligosaccharides J. Biol. Chem. 263 3539-41

[80] Zaloba P, Bailey-Elkin B A, Derksen M and Mark B L 2016 Structural and biochemical insights into the peptidoglycan hydrolase domain of FlgJ from Salmonella typhimurium PLoS One 11 e0149204 